\title{
Le statut du fou au cours des âges
}

\section{Jean Martin}

Dr méd., membre de la rédaction

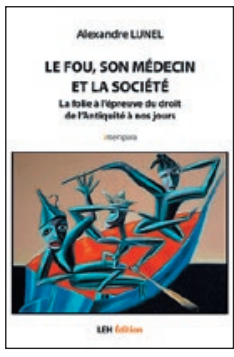

Alexandre Lunel

Le fou, son médecin et la société

La folie à l'épreuve du droit de l'Antiquité à nos jours

Bordeaux: LEH Edition, 2019, 194 pages.

Le statut de la personne présentant des troubles mentaux, sa place dans la société qui cherche à l'inclure ou au contraire - le plus souvent - à l'exclure, y compris la défense de ses intérêts, est un grand sujet. De droit au premier chef, avec de nombreux points de contact et interactions avec la médecine: les médecins sont appelés à soigner ces personnes d'une part et, d'autre part, en tant qu'experts, à se prononcer sur leur capacité de discernement et leur responsabilité - en matière pénale aussi bien que civile. Un domaine passionnant à plusieurs égards, qui connaît des "flux» en fonction de l'évolution des idées quant aux droits des personnes et, aujourd'hui, du développement des neurosciences qui pourraient apporter des éléments potentiellement déstabilisants pour les doctrines pénales en place. «La médecine et la police ont en commun de pouvoir porter atteinte à l'intégrité d'autrui afin de protéger la société, tandis qu'il incombe à la justice de fixer les règles encadrant ces interventions», rappelle la préface.

Alexandre Lunel, juriste et historien, livre un ouvrage très bien informé, dense, sur les idées et les régimes juridiques depuis le «legs» de la Grèce et de Rome. Deux grandes parties: la première de l'Antiquité à la fin de l'Ancien régime, la seconde intitulée "L’affirmation d'un statut du malade mental aux XIX ${ }^{\mathrm{e}}$ et $\mathrm{XX}^{\mathrm{e}}$ siècles». Les premières sections traitant largement de ce qui prévaut en Europe, puis c'est la situation française qui est discutée en détail - la présentation des grands débats et évolutions étant pertinente par analogie pour d'autres pays. Si le médecin de l'Antiquité a longuement disserté sur la folie, c'est le juriste romain qui va définir son statut. Jusqu'au début de notre ère, la protection du fou et de ses intérêts est essentiellement dévolue à ses proches, mais "progressivement, au cours de l'Empire, s'opère une révolution vers un transfert de compétence de la famille à la chose publique». Intéressant de noter par exemple une disposition protectrice comme celle-ci: si l'un des conjoints présente des troubles mentaux, aucune rupture du mariage n'est permise, «car rien n'est plus conforme à la nature humaine pour le mari que de prendre part aux accidents fortuits de sa femme ou la femme à ceux de son mari». Entre autres points, l'irresponsabilité pénale du «furieux» retient l'attention du droit romain.

S'agissant du Moyen-Age, intéressante discussion de la «médicalisation de la sorcellerie», dont ont été accusés des fous - et beaucoup de femmes -, entrainant la mort sur le bûcher de milliers de personnes entre le $\mathrm{XV}^{\mathrm{e}}$ et le XVII ${ }^{\mathrm{e}}$ siècle. Un médecin rhénan, Johann Wier, prend courageusement position contre ces procès. Des théologiens s'insurgent, l'un d'entre eux prédisant que «si les médecins sont admis à donner leur avis, on ne brûlera [plus] personne»! - Ils sont malheureusement plus écoutés par les juges que le médecin Wier. Ensuite, les $\mathrm{XVII}^{\mathrm{e}}$ et XVIII ${ }^{\mathrm{e}}$ siècles sont une grande période d'enfermement des malades dans des hospices, hôpitaux, maisons de force et dépôts de mendicité (!), «les fous y rejoignant la cohorte des déviants sociaux, mendiants, prostituées et autres galeux».

La Révolution française voit la naissance progressive de la psychiatrie, avec Philippe Pinel en particulier, qui démontre que la folie peut être soignée et qu'il est possible de communiquer avec le sujet aliéné. Néanmoins, la condition des malades ne s'améliore guère en pratique. Est promulguée en France une loi de 1838 dont la genèse a été influencée par les aliénistes et qui fait passer du «fou social au fou médical». Il y a alors des débats entre plusieurs médecins éminents: pour certains, la protection de la liberté individuelle du malade est au cœur de la problématique, d'autres craignent qu'on ne tienne pas assez compte de l'intérêt des familles et que trop de conditions rendent la loi inapplicable - à savoir gênent les placements.

Les dernières sections du livre décrivent la mise en place au XIX ${ }^{e}$ siècle de structures d'accueil, les asiles départementaux, les critiques que certains d'entre eux ont suscitées, puis au $\mathrm{XX}^{\mathrm{e}}$ siècle, dès l'entre-deuxguerres, les prémices de l'hospitalisation libre. Titre du dernier chapitre, «L'asile, chronique d'une mort annoncée», sur les évolutions récentes: mouvement d'antipsychiatrie, sectorisation psychiatrique, loi Evin de 1990 notamment. Est évoquée, "ultime chapitre de notre histoire de la folie», l'arrivée des médiateurs de santépairs et pairs-aidants: anciens usagers désormais établis dans les équipes de soins dans plusieurs pays. 